\title{
Round Robin Tests to Determine Fiber Content of Carbon Fiber-Reinforced Thermoplastic Composites by Combustion and Thermogravimetry
}

\author{
Masahiro Funabashi, ${ }^{1,2}$ Fumi Ninomiya, ${ }^{2}$ Akihiro Oishi, ${ }^{1,2}$ Wataru Mizuno, ${ }^{1,3}$ \\ Kimitaka Tahira, ${ }^{1,4}$ Shogo Tanaka, ${ }^{1,5}$ and Masao Kunioka ${ }^{1,2}$ \\ ${ }^{1}$ Polymer Subcommittee of the Industrial Technology Cooperative Promotion Committee, Umezono 1-1-1, Tsukuba, \\ Ibaraki 305-8560, Japan \\ ${ }^{2}$ Research Institute for Sustainable Chemistry, National Institute of Advanced Industrial Science and Technology (AIST), \\ Higashi 1-1-1, Tsukuba, Ibaraki 305-8565, Japan \\ ${ }^{3}$ Human Life Technology Research Institute, Toyama Industrial Technology Center, Futagami-cho 150, Takaoka, \\ Toyama 933-0981, Japan \\ ${ }^{4}$ Western Region Industrial Research Center, Hiroshima Prefectural Technology Research Institute, Agaminami 2-10-1, \\ Kure, Hiroshima 737-0004, Japan \\ ${ }^{5}$ Industrial Research Institute of Shizuoka Prefecture, Makigaya 2078, Aoi-ku, Shizuoka-shi, Shizuoka 421-1298, Japan
}

Correspondence should be addressed to Masahiro Funabashi; m.funabashi@aist.go.jp

Received 24 May 2017; Revised 14 September 2017; Accepted 16 October 2017; Published 14 November 2017

Academic Editor: Yves Grohens

Copyright (C) 2017 Masahiro Funabashi et al. This is an open access article distributed under the Creative Commons Attribution License, which permits unrestricted use, distribution, and reproduction in any medium, provided the original work is properly cited.

\begin{abstract}
To propose methods to determine the fiber content of carbon fiber-reinforced plastics (CFRP) for the International Organization for Standardization, the fiber contents of CFRP with polyamide- 6 were measured using a combustion method based on ISO 14127 and a thermogravimetry method based on the modified ISO 9924-3 under a round robin test managed by the Polymer Subcommittee of the Industrial Technology Cooperative Promotion Committee in Japan. In the combustion method, the fiber contents of the CFRTP $(\sim 0.3 \mathrm{~g})$ were determined by the mass of carbon fiber remaining after burning (ISO 14127). The fiber contents in weight of the CFRTP with 8, 9, or 10 plies were determined to be $55.720 \%, 61.088 \%$, or $65.326 \%$, respectively, by 17 research institutes. In the thermogravimetry method, the fiber contents of the CFRTP $(\sim 10 \mathrm{mg})$ were determined by the mass of carbon fiber remaining after heating it to $600^{\circ} \mathrm{C}$ in nitrogen gas using thermogravimetry apparatus (modified ISO 9924-3). The fiber contents of the CFRTP with 8,9 , or 10 plies were determined to be $56.908 \%, 61.579 \%$, or $64.819 \%$, respectively, by 8 research institutes. It was confirmed that thermogravimetry method was as accurate as the combustion method based on ISO 14127.
\end{abstract}

\section{Introduction}

Currently, carbon fiber-reinforced plastics (CFRP) are widely used as structural materials in construction, vehicles, airplanes, and so on. Initially, epoxy resin was used as the matrix resin for the CFRP [1-5]. Thermoplastics have, however, replaced epoxy resin for some of the abovementioned products. Carbon fiber-reinforced thermoplastics (CFRTPs) are manufactured mainly using flow molding, such as extrusion and injection molding [6]. Therefore, carbon fiber content distribution in CFRTP products could be wider than that in CFRP with epoxy resin since the thermoplastics could flow during heat process, such as heat pressing and aging processes. It is important to control the carbon fiber content of CFRP products, because the carbon fiber content strongly affects their mechanical properties. Methods to determine the carbon fiber content of CFRP are regulated by two international standards: the one set by the International Organization for Standardization (ISO 14127, "Carbon-FibreReinforced Composites-Determination of the Resin, Fibre 
and Void Contents") and the one proposed by the American Society for Testing and Materials (ASTM D3171-15, titled "Standard Test Methods for Constituent Content of Composite Materials"). The fiber content by weight of CFRP is measured after removing the resin part of the CFRP using strong acids according to ISO 14127 and ASTM D3171-15 [7] or by combustion in nitrogen gas according to ISO 14127 [8]. However, methods that do not use combustion or strong acids are safer and eliminate the need to treat liquid wastes arising from the use of the acids. Fiber contents of CFRP have been measured in several studies to determine the characteristics of CFRP [7-10]. The relationship between the fiber contents and thermal diffusivity measured by IR thermography was studied to provide a new method for measuring the fiber content of composites $[9,10]$.

Recently, many manufacturers have developed apparatus for thermogravimetric analysis using thermogravimetry (TG) apparatus. It is possible to determine the resin content in CFRP to choose the appropriate temperature program and purge gas, since the thermal degradation behavior of resin is different from that of carbon fiber. The international standard ISO 9924-3, titled "Rubber and Rubber Products-Determination of Composition of Vulcanizates and Uncured Compounds by Thermogravimetry-Part 3: Hydrocarbon Rubbers, Halogenated Rubbers and Polysiloxane Rubbers after Extraction," was published in the ISO technical committee (TC) 45 "Rubber and Rubber Products" [11]. The weight ratio of the rubber part, carbon filler, metal, and inorganic fillers can be determined using this standard. We tried to apply to a CFRP to determine its carbon fiber content instead of doing so by carbon black content of the rubber product by TG. Usually, $\sim 10 \mathrm{mg}$ of a specimen is used for thermogravimetry. On the other hand, $\sim 0.3 \mathrm{~g}$ of a specimen is used for measurement by method as described in ISO 14127. This small amount of specimen offers better results in the investigation of the fiber content distribution at different locations of a CFRP product than that obtained using the method proposed by ISO 14127.

The round robin tests (RRT) for CFRTP on physical properties, such as mechanical properties and degradation, were undertaken by the Polymer Subcommittee of the Industrial Technology Cooperative Promotion Committee, comprising Japanese local governmental research institutes and the National Institute of Advanced Industrial Science and Technology (AIST, Japan) [12] from 2012 to 2016. The round robin test of fiber contents of CFRTP in this study is one of the results. The fiber contents of CFRTP in the tests were measured by the combustion and strong acid according to ISO 14127 and were measured by TG method according to ISO 9924-3. The author proposes a new standard as fiber content of CFRP by TG method, to be considered under ISO/TC 61, "Plastics."

The fiber contents were measured by three methods, which were compared to propose a new, optimal method for fiber content measurements. The first method involves removing resin by combustion according to ISO 14127 . The second removes resin by thermogravimetry. The third removes resin using strong acids.
TABLE 1: Temperature profile for the thermogravimetry (TG) experiments to determine the fiber content of the carbon fiber-reinforced thermoplastic (CFRTP).

\begin{tabular}{lccccc}
\hline Step & $\begin{array}{c}\text { Start tem- } \\
\text { perature } \\
{ }^{\circ} \mathrm{C}\end{array}$ & $\begin{array}{c}\text { End tem- } \\
\text { perature } \\
{ }^{\circ} \mathrm{C}\end{array}$ & $\begin{array}{c}\text { Heating } \\
\text { rate } \\
{ }^{\circ} \mathrm{C} / \mathrm{min}\end{array}$ & $\begin{array}{c}\text { Period } \\
\text { min }\end{array}$ & $\begin{array}{c}\text { Purging } \\
\text { gas }\end{array}$ \\
\hline 1 & 30 & 600 & 10 & 57 & $\mathrm{~N}_{2}$ \\
2 & 600 & 400 & -10 & 20 & $\mathrm{~N}_{2}$ \\
3 & 400 & 400 & 0 & 2 & $\mathrm{~N}_{2}$ \\
4 & 400 & 800 & 10 & 40 & Air \\
5 & 800 & 800 & 0 & 20 & Air \\
\hline
\end{tabular}

\section{Experimental}

2.1. Carbon Fiber-Reinforced Thermoplastic Sample. Square boards ( $350 \mathrm{~mm} \times 350 \mathrm{~mm} ; 2 \mathrm{~mm}$ thickness) of carbon fiberreinforced thermoplastic were molded from 8,9 , and 10 laminates (plies) of pre-preg made of plain weave clothes of carbon fibers and polycaprolactam produced by Ichimura Sangyo Co., Ltd. (Ishikawa, Japan). These boards were cut into $1 \mathrm{~cm}^{2}$ samples by Taihei Corporation (Toyama, Japan).

2.2. Fiber Content Measurement by Combustion. Fiber content measurements by combustion were performed according to ISO 14127. For this test, $1 \mathrm{~cm}^{2}$ specimens were used without further cutting. The weight of each specimen was measured using an electric balance. The specimen was bound with nichrome wire to prevent carbon fibers from flying away during combustion. Using tweezers to hold it, the nichromewire-bound specimen was introduced to a Bunsen burner flame, a little above the top of the reducing zone of the flame, and heated until its bottom surface became red hot. Then, the specimen was inverted and maintained until the other surface became red hot. When all the resin had been burnt off, the red flame disappeared. The remainder of the specimen was weighed. The fiber content by weight was derived by dividing the weight of the specimen after burning by the weight of the original specimen.

2.3. Fiber Content Measurement by Thermogravimetric Analysis. The fiber content of the CFRTP composite sample was measured by combustion of the matrix resin of composites using TG apparatus. The test procedure was almost the same as that outlined by ISO 9924-3 for the determination of the composition of rubber products. Sample pans made of $\mathrm{Al}_{2} \mathrm{O}_{3}$ (a platinum pan can also be used) with a diameter of $5.2 \mathrm{~mm}$ and height of $5 \mathrm{~mm}$ were used for thermogravimetry. Specimens weighing 5-20 mg were scratched off of the $1 \mathrm{~cm}^{2}$ specimens by hand using a cutter knife. The temperature was controlled in steps as shown in Table 1 . The temperature ranges, heating rates, and purged gas for all steps are shown in Table 1. Nitrogen gas and dry air were employed as the purging gases at a flow rate of $200 \mathrm{~mL} / \mathrm{min}$. Mass change (\%) from the original mass of the specimen was determined for all temperature and time profiles. The fiber content by weight was defined as the mass percent difference between the mass at the end of step 3 and that at the end of step 5. 
TABLE 2: Calculated fiber content of the CFRTP with 9 plies after resin removal by combustion according to ISO 14127.

\begin{tabular}{|c|c|c|c|c|c|c|c|c|c|}
\hline \multirow{2}{*}{ Organization } & \multirow{2}{*}{$\begin{array}{l}\text { Number of } \\
\text { specimens }\end{array}$} & \multicolumn{2}{|c|}{ Initial weight (g) } & \multicolumn{2}{|c|}{$\begin{array}{l}\text { Weight with wire } \\
\text { (g) }\end{array}$} & \multicolumn{2}{|c|}{$\begin{array}{l}\text { Weight after } \\
\text { combustion (g) }\end{array}$} & \multicolumn{2}{|c|}{$\begin{array}{c}\text { Fiber content in } \\
\text { weight }(\%)\end{array}$} \\
\hline & & Average & $\begin{array}{l}\text { Standard } \\
\text { deviation }\end{array}$ & Average & $\begin{array}{l}\text { Standard } \\
\text { deviation }\end{array}$ & Average & $\begin{array}{l}\text { Standard } \\
\text { deviation }\end{array}$ & Average & $\begin{array}{l}\text { Standard } \\
\text { deviation }\end{array}$ \\
\hline A & 5 & 0.32436 & 0.00297 & 0.36034 & 0.00350 & 0.23474 & 0.00393 & 61.279 & 0.261 \\
\hline B & 5 & 0.31903 & 0.00408 & 0.35990 & 0.00434 & 0.23580 & 0.00261 & 61.101 & 0.157 \\
\hline $\mathrm{C}$ & 5 & 0.32410 & 0.00236 & 0.35404 & 0.00242 & 0.22764 & 0.00107 & 61.002 & 0.256 \\
\hline $\mathrm{D}$ & 3 & 0.32455 & 0.00199 & 0.36442 & 0.00209 & 0.23810 & 0.00339 & 61.082 & 0.407 \\
\hline $\mathrm{E}$ & 3 & 0.32247 & 0.00102 & 0.34893 & 0.00696 & 0.22253 & 0.00625 & 60.802 & 0.261 \\
\hline $\mathrm{F}$ & 3 & 0.32291 & 0.00539 & 0.83230 & 0.05987 & 0.70320 & 0.06174 & 60.028 & 0.538 \\
\hline G & 3 & 0.31970 & 0.00417 & 0.36330 & 0.01383 & 0.23907 & 0.01234 & 61.143 & 0.330 \\
\hline $\mathrm{H}$ & 3 & 0.32203 & 0.00272 & 0.39320 & 0.00545 & 0.26443 & 0.00242 & 60.020 & 0.600 \\
\hline I & 3 & 0.32167 & 0.00125 & 0.38700 & 0.00245 & 0.26300 & 0.00707 & 61.447 & 1.672 \\
\hline $\mathrm{J}$ & 3 & 0.32107 & 0.00333 & 0.38653 & 0.00836 & 0.26223 & 0.00651 & 61.287 & 0.199 \\
\hline K & 3 & 0.32297 & 0.00208 & 0.37904 & 0.01112 & 0.25272 & 0.01276 & 60.889 & 0.362 \\
\hline $\mathrm{L}$ & 5 & 0.32298 & 0.00189 & 0.34562 & 0.00201 & 0.22252 & 0.00129 & 61.887 & 0.337 \\
\hline M & 5 & 0.32144 & 0.00295 & 0.36070 & 0.00294 & 0.23604 & 0.00145 & 61.220 & 0.340 \\
\hline $\mathrm{N}$ & 5 & 0.32338 & 0.00230 & 0.37468 & 0.00747 & 0.25030 & 0.00793 & 61.537 & 0.570 \\
\hline $\mathrm{O}$ & 5 & 0.32365 & 0.00179 & 0.38249 & 0.00141 & 0.25691 & 0.00200 & 61.201 & 0.286 \\
\hline $\mathrm{P}$ & 5 & 0.32286 & 0.00453 & 0.36392 & 0.00787 & 0.23838 & 0.00580 & 61.120 & 0.299 \\
\hline Q & 3 & 0.32433 & 0.00125 & 0.37333 & 0.00189 & 0.24833 & 0.00245 & 61.459 & 0.002 \\
\hline Total & 67 & 0.32278 & 0.00324 & 0.38813 & 0.09803 & 0.26265 & 0.09726 & 61.129 & 0.657 \\
\hline Interlaboratory & 17 & 0.323 & 0.002 & 0.396 & 0.110 & 0.270 & 0.109 & 61.088 & 0.461 \\
\hline
\end{tabular}

2.4. Fiber Content Measurement by Acid Degradation Method. Fiber content measurements using strong acids were performed according to ISO 14127. For this test, $1 \mathrm{~cm}^{2}$ specimens were used without further cutting. The weight of each specimen was measured using an electric balance. Using a measuring cylinder, $20 \mathrm{ml}$ of concentrated sulfuric acid $(36 \mathrm{~N})$ was measured and poured into a $200 \mathrm{ml}$ beaker. The specimen was introduced in the concentrated sulfuric acid and the beaker was covered with a watch glass. To dissolve the resin, the beaker was heated on a hot-plate stirrer (at $\sim 160^{\circ} \mathrm{C}$ ) so that the sulfuric acid began to fume. When all the resin had dissolved and the sulfuric acid solution had become dark brown in color, heating was stopped. About $10 \mathrm{ml}$ of a hydrogen peroxide solution $(\sim 30 \%)$ was added slowly. The beaker was heated on a hot-plate stirrer again (at $\sim 160^{\circ} \mathrm{C}$ ). When all the fibers floated up to the surface, leaving the sulfuric acid solution clear, the beaker was cooled to room temperature. The contents of the beaker were filtered through a glass filter, using vacuum suction, to separate the fibers. The fibers retained on the filter were washed with $\sim 100 \mathrm{ml}$ of distilled water. Then, the fibers were washed with $20 \mathrm{ml}$ of acetone. The glass filter was placed in an air circulation oven and dried at $120^{\circ} \mathrm{C}$ for $1.5 \mathrm{~h}$. It was then placed in a desiccator without a vacuum oven for $30 \mathrm{~min}$ to cool to room temperature. The glass filter and fiber were weighed using an electric balance. The fiber content by weight was derived by dividing the weight of the specimen after dissolution by the weight of the original specimen.
2.5. RRT for Fiber Content Measurements. The test protocols of RRT for fiber content measurements described in Sections 2.2 to 2.4 were managed by the Polymer Subcommittee of the Industrial Technology Cooperative Promotion Committee. All of the operators who measured fiber contents joined the meeting of the above committee and discussed detailed procedure of RRT. The operators understood the procedures of RRT. Therefore, RRT in this paper should be treated as a RRT measured by the experts.

2.6. Observation of CFRTP after TG Measurement. Residues of CFRTP after TG measurements were observed using an USB camera (Shodensha, Osaka, Japan).

\section{Results and Discussion}

3.1. Fiber Content of CFRTP Samples Obtained by the Combustion Method. RRT results for fiber content measurements for CFRP samples with 9 plies by combustion are shown in Table 2. The average value and the standard deviation are expressed for each organization. The average and standard deviation of all of the results were calculated and are shown as "Total" in the table. The average value and standard deviation of fiber contents agree well with each other. Most of the standard deviation values are less than $1 \%$. The average and deviation among organizations are also shown as "Interlaboratory" in the table. These deviations are less than $1 \%$, as well. This result suggests good repeatability and reproducibility 
TABLE 3: Calculated fiber content of CFRTP with 8 plies after resin removal by combustion according to ISO 14127.

\begin{tabular}{|c|c|c|c|c|c|c|c|c|c|}
\hline \multirow{2}{*}{ Organization } & \multirow{2}{*}{$\begin{array}{l}\text { Number of } \\
\text { specimens }\end{array}$} & \multicolumn{2}{|c|}{ Initial weight (g) } & \multicolumn{2}{|c|}{ Weight with wire (g) } & \multicolumn{2}{|c|}{$\begin{array}{l}\text { Weight after } \\
\text { combustion (g) }\end{array}$} & \multicolumn{2}{|c|}{$\begin{array}{c}\text { Fiber content in } \\
\text { weight }(\%)\end{array}$} \\
\hline & & Average & $\begin{array}{l}\text { Standard } \\
\text { deviation }\end{array}$ & Average & $\begin{array}{l}\text { Standard } \\
\text { deviation }\end{array}$ & Average & $\begin{array}{l}\text { Standard } \\
\text { deviation }\end{array}$ & Average & $\begin{array}{l}\text { Standard } \\
\text { deviation }\end{array}$ \\
\hline A & 5 & 0.35274 & 0.01479 & 0.38692 & 0.01850 & 0.22674 & 0.00457 & 54.685 & 2.435 \\
\hline B & 5 & 0.35354 & 0.01429 & 0.38440 & 0.01455 & 0.22830 & 0.00572 & 55.886 & 1.243 \\
\hline $\mathrm{C}$ & 3 & 0.35743 & 0.00507 & 0.38793 & 0.00332 & 0.22593 & 0.00222 & 54.686 & 0.645 \\
\hline $\mathrm{D}$ & 3 & 0.35775 & 0.00791 & 0.60993 & 0.04229 & 0.46050 & 0.05405 & 58.208 & 3.702 \\
\hline $\mathrm{E}$ & 3 & 0.35626 & 0.00470 & 0.42498 & 0.00103 & 0.26643 & 0.00801 & 55.513 & 1.430 \\
\hline $\mathrm{F}$ & 5 & 0.35676 & 0.01331 & 0.37982 & 0.01377 & 0.22636 & 0.00217 & 57.066 & 2.264 \\
\hline G & 5 & 0.35988 & 0.00887 & 0.39906 & 0.00860 & 0.23804 & 0.00247 & 55.279 & 1.009 \\
\hline $\mathrm{H}$ & 5 & 0.36188 & 0.00611 & 0.41857 & 0.00363 & 0.25367 & 0.00384 & 54.440 & 0.578 \\
\hline Total & 34 & 0.35701 & 0.01115 & 0.41507 & 0.06467 & 0.25659 & 0.06686 & 55.647 & 2.194 \\
\hline Interlaboratory & 8 & 0.357 & 0.003 & 0.424 & 0.072 & 0.266 & 0.075 & 55.720 & 1.227 \\
\hline
\end{tabular}

TABLE 4: Calculated fiber content of CFRTP with 10 plies after resin removal by combustion according to ISO 14127.

\begin{tabular}{|c|c|c|c|c|c|c|c|c|c|}
\hline \multirow{2}{*}{ Organization } & \multirow{2}{*}{$\begin{array}{l}\text { Number of } \\
\text { specimens }\end{array}$} & \multicolumn{2}{|c|}{ Initial weight (g) } & \multicolumn{2}{|c|}{$\begin{array}{l}\text { Weight with wire } \\
\text { (g) }\end{array}$} & \multicolumn{2}{|c|}{$\begin{array}{l}\text { Weight after } \\
\text { combustion }(\mathrm{g})\end{array}$} & \multicolumn{2}{|c|}{$\begin{array}{c}\text { Fiber content in } \\
\text { weight }(\%)\end{array}$} \\
\hline & & Average & $\begin{array}{l}\text { Standard } \\
\text { deviation }\end{array}$ & Average & $\begin{array}{l}\text { Standard } \\
\text { deviation }\end{array}$ & Average & $\begin{array}{l}\text { Standard } \\
\text { deviation }\end{array}$ & Average & $\begin{array}{l}\text { Standard } \\
\text { deviation }\end{array}$ \\
\hline A & 5 & 0.30292 & 0.00241 & 0.33904 & 0.00413 & 0.23184 & 0.00387 & 64.613 & 0.401 \\
\hline B & 5 & 0.29838 & 0.00526 & 0.32828 & 0.00524 & 0.22596 & 0.00248 & 65.714 & 0.401 \\
\hline $\mathrm{C}$ & 3 & 0.29683 & 0.00175 & 0.32607 & 0.00454 & 0.22317 & 0.00443 & 65.334 & 0.051 \\
\hline $\mathrm{D}$ & 3 & 0.30323 & 0.00445 & 0.83727 & 0.08050 & 0.73040 & 0.08264 & 64.769 & 1.263 \\
\hline $\mathrm{E}$ & 3 & 0.30830 & 0.00963 & 0.37602 & 0.00851 & 0.26972 & 0.00370 & 65.537 & 0.505 \\
\hline $\mathrm{F}$ & 5 & 0.30240 & 0.00367 & 0.32672 & 0.00502 & 0.22382 & 0.00204 & 65.981 & 0.804 \\
\hline G & 5 & 0.30097 & 0.00394 & 0.36073 & 0.00414 & 0.25585 & 0.00141 & 65.161 & 0.567 \\
\hline$\underline{\mathrm{H}}$ & 5 & 0.30124 & 0.00359 & 0.34034 & 0.00349 & 0.23640 & 0.00124 & 65.502 & 0.605 \\
\hline Total & 34 & 0.30161 & 0.00542 & 0.38511 & 0.14359 & 0.28057 & 0.14284 & 65.346 & 0.779 \\
\hline Interlaboratory & 8 & 0.302 & 0.003 & 0.404 & 0.164 & 0.300 & 0.164 & 65.326 & 0.433 \\
\hline
\end{tabular}

of this method. No significant difference was noted among the results from different organizations. These results may be caused that all the operators joining the RRT were experts for the measurements of RRT.

The results of RRT for the CFRP with 8 plies and CFRP with 10 plies are shown in Tables 3 and 4. The tendencies noted were almost the same as those observed in the RRT for the CFRP with 9 plies. Thus, no significant difference was noted among results obtained by different organizations. The standard deviations of the fiber contents are bigger than those in Table 2.

3.2. Fiber Content of CFRTP Samples Obtained by TG. The temperature profile was almost the same as that mentioned by ISO 9924-3. The mass change of CFRP with 9 plies by TG is shown in Figure 1. Time dependence of the mass change of the CFRTP specimen and temperature are shown in the figure. The curve of mass change reached a constant at $600^{\circ} \mathrm{C}$, which marks the end of step 1 mentioned in Table 1 . The mass change

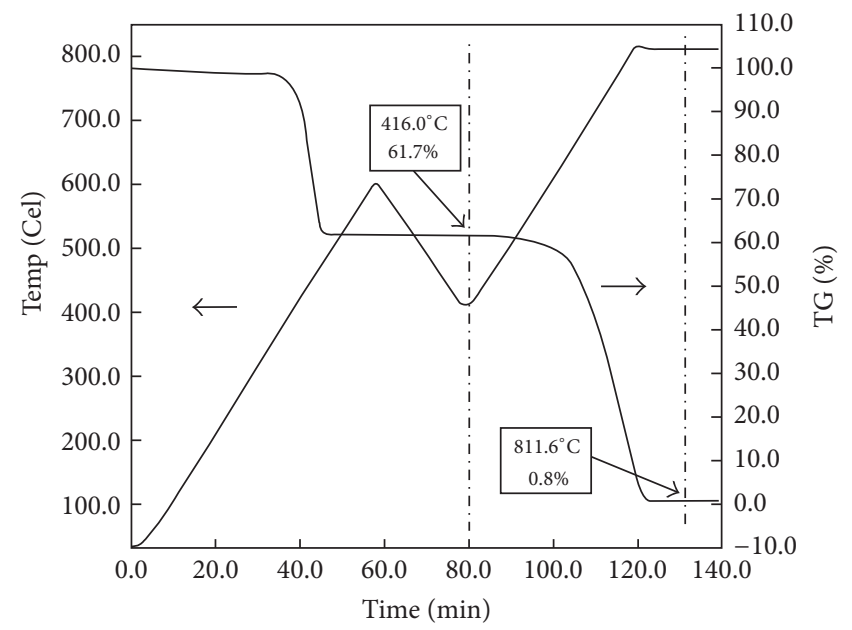

FIgURE 1: Temperature and mass change during fiber content measurement of CFRTP sample with 9 plies under nitrogen (from $\mathrm{RT}$ to $\left.600^{\circ} \mathrm{C}\right)$ and air $\left(400\right.$ to $\left.800^{\circ} \mathrm{C}\right)$ by thermogravimetry. 


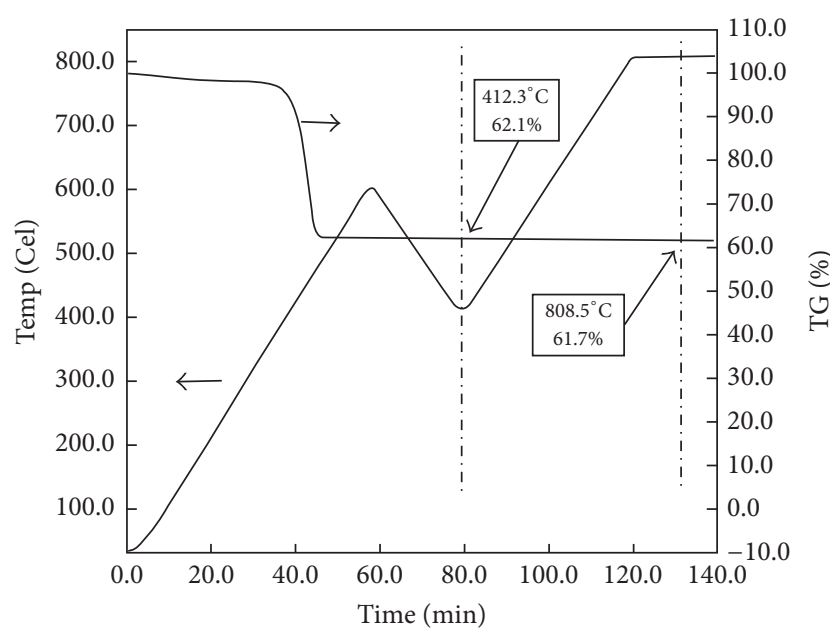

FIGURE 2: Temperature and mass change of CFRTP sample with 9 plies during heating under nitrogen gas by thermogravimetry.

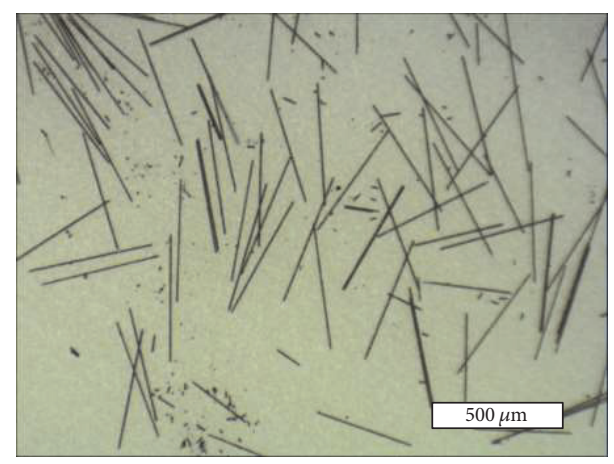

FIGURE 3: Optical microscope image of CFRTP residue obtained after the thermogravimetric test under nitrogen gas up to $600^{\circ} \mathrm{C}$.

of CFRTP with 9 plies by TG with the same temperature profiles as that in Figure 1 under nitrogen gas is shown in Figure 2. The difference between the results shown in Figures 1 and 2 indicates that the resin part of CFRTP may have been removed by thermal degradation under nitrogen gas, since carbon fiber is not degraded by heating under nitrogen gas. The optical microscope images of the residue using an USB camera are shown in Figures 3 and 4. Figure 3 corresponds to the image of residue after step 3, shown in Figure 1, and Figure 4 corresponds to the image of residue after step 5, shown in Figure 2. These images show that carbon fibers are not degraded under nitrogen gas.

The RRT results for fiber content measurements for the CFRTP with 9 plies are shown in Table 5. The average value and standard deviation are expressed for each organization. The average and standard deviation of all of the results were calculated and are shown as "Total" in the table. The average value and standard deviation of the fiber contents agree well with each other. Most standard deviation values are less than $1 \%$, implying good repeatability and reproducibility of this method. No significant difference was noted among the results obtained by different organizations.

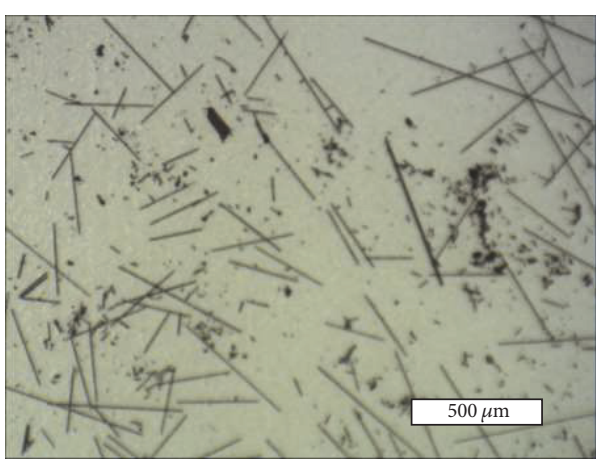

FIGURE 4: Optical microscope image of CFRTP residues obtained after the thermogravimetric test under nitrogen gas up to $800^{\circ} \mathrm{C}$.

The results for the CFRTP with 8 plies and 10 plies are shown in Tables 6 and 7. The tendencies seen were almost the same as that noted for the CFRTP with 9 plies. No significant difference was noted among results obtained by different organizations. The standard deviations are sufficiently small for reasonable evaluation of the carbon fiber content of CFRP, although the standard deviation values are greater than those in Table 5 .

This new evaluation method of determining carbon fiber content of CFRP by thermogravimetry will be proposed as a new ISO standard.

3.3. Fiber Content of CFRTP Samples Obtained by Acid Degradation. Another method of determination of the fiber content of CFRP using strong acid is also regulated by ISO 14127. The carbon fiber content of CFRTPs determined by this method was compared with values obtained by other methods. Table 8 lists the fiber content of CFRTP samples with 10 plies measured by the acid degradation method. The average value and standard deviation of the fiber content were almost the same as those obtained by the combustion method, shown in Table 4, and those obtained by thermogravimetry, shown in Table 7. No significant difference was noted among the fiber contents of the CFRTP obtained in this study by three different methods.

3.4. Accuracies of Fiber Contents Measurements. The samples of fiber contents in this paper were mechanically cut from the plates derived from pre-preg made of plain weave clothes of carbon fibers. Before the mechanical cutting for samples, the edge parts of plates where the weave clothes were not isotropic were eliminated. An amount of carbon fiber of clothes is almost the same, when width and length of samples are the same. If width and length of samples are the same, the weight of samples depends on only weight of the resin in the samples. In this case, fiber content of samples is proportion of weight of samples, since the weight of carbon fiber is the same. The distribution of sample weight is closely related to the distribution of fiber content of the sample. It is thought that the deviations of fiber contents in this paper can be estimated as the deviation of the sample weight. The whole samples were used for fiber content by combustion method. Therefore, the fiber content distributions of CFRTP with 8 , 


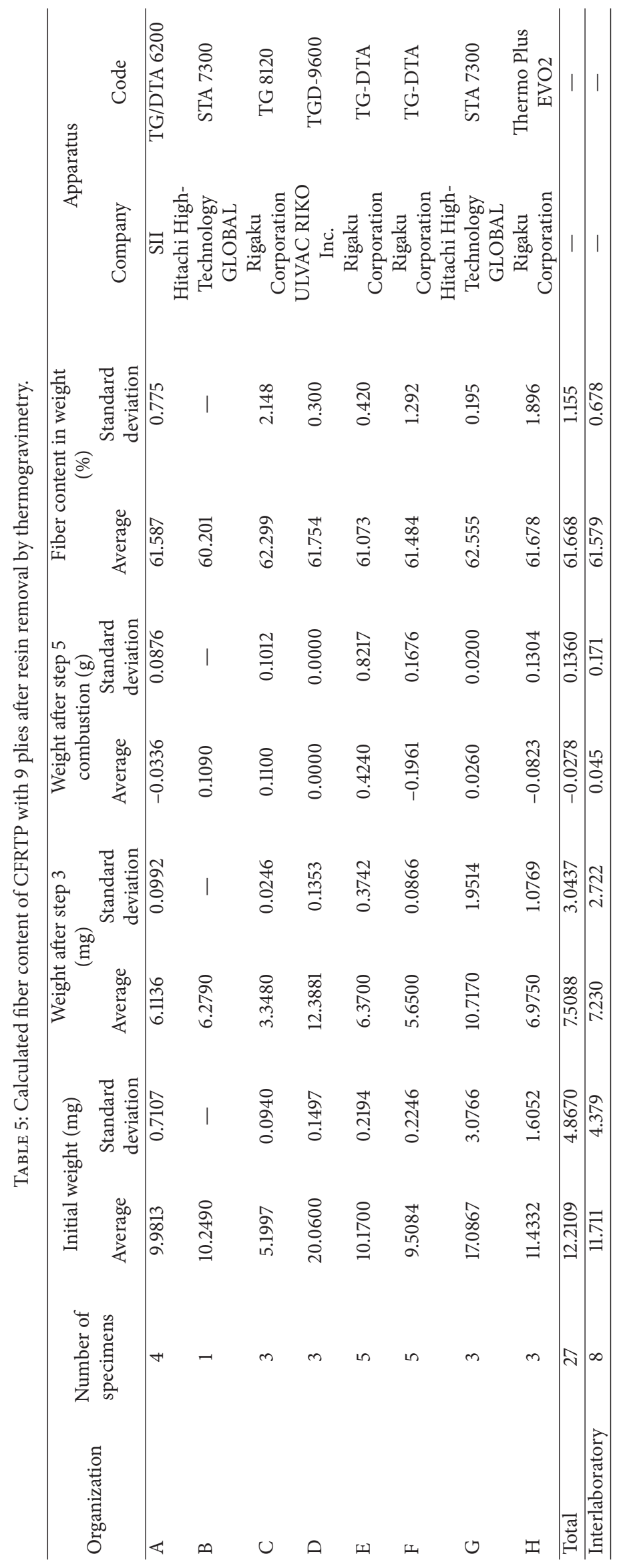




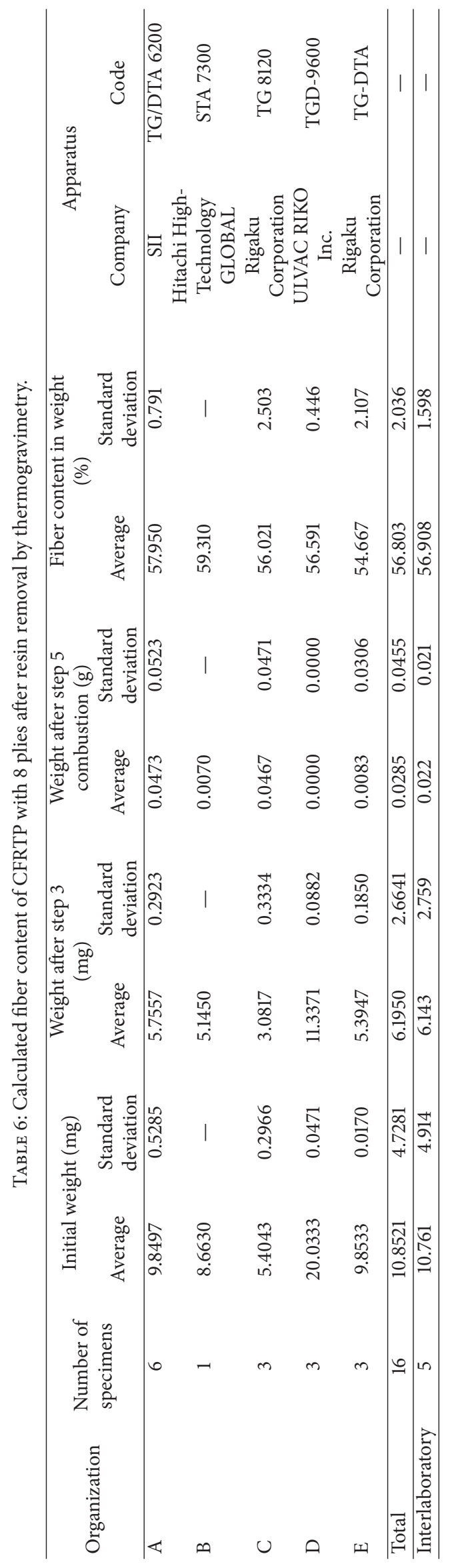




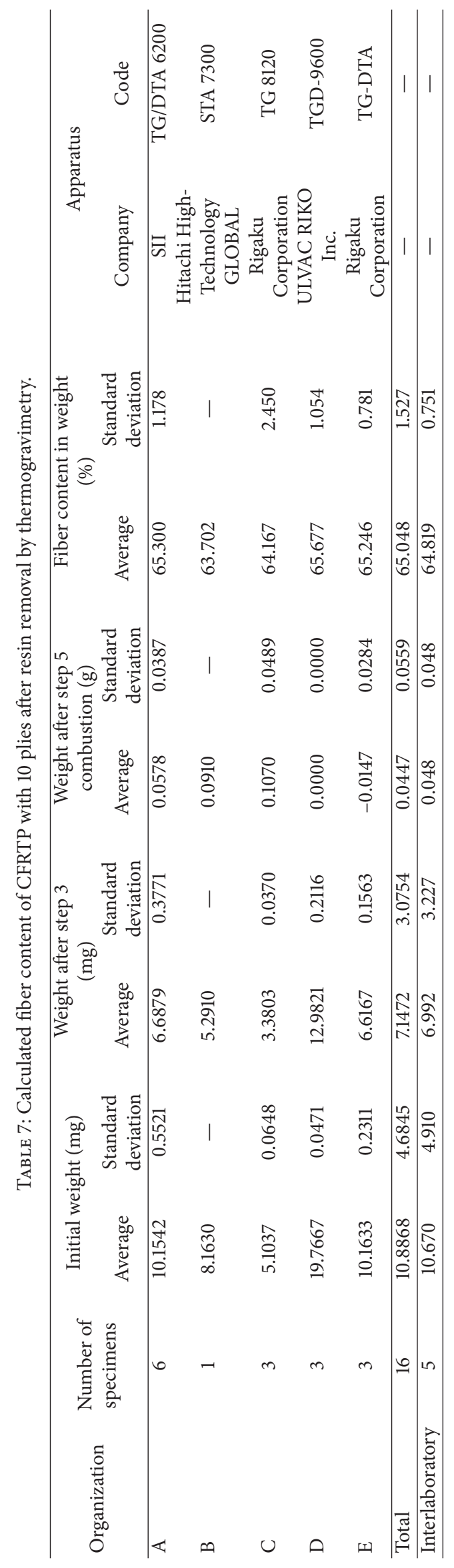


TABLE 8: Fiber content of CFRTP samples with 10 plies measured by acid degradation method.

\begin{tabular}{|c|c|c|c|c|c|c|c|c|c|}
\hline \multirow[t]{2}{*}{ Organization } & \multirow{2}{*}{$\begin{array}{l}\text { Number of } \\
\text { specimens }\end{array}$} & \multicolumn{2}{|c|}{ Initial weight $(\mathrm{g})$} & \multicolumn{2}{|c|}{$\begin{array}{l}\text { Weight after of } \\
\text { Gooch crucible (g) }\end{array}$} & \multicolumn{2}{|c|}{$\begin{array}{l}\text { Weight of Gooch } \\
\text { crucible and fibers } \\
\text { (g) }\end{array}$} & \multicolumn{2}{|c|}{$\begin{array}{l}\text { Fiber content in } \\
\text { weight }(\%)\end{array}$} \\
\hline & & Average & $\begin{array}{l}\text { Standard } \\
\text { deviation }\end{array}$ & Average & $\begin{array}{l}\text { Standard } \\
\text { deviation }\end{array}$ & Average & $\begin{array}{l}\text { Standard } \\
\text { deviation }\end{array}$ & Average & $\begin{array}{l}\text { Standard } \\
\text { deviation }\end{array}$ \\
\hline A & 2 & 0.3038 & 0.0077 & 38.8945 & 0.2316 & 39.0904 & 0.2269 & 64.474 & 0.076 \\
\hline
\end{tabular}

9, and 10 plies are estimated as the initial weight of samples expressed in Tables 3, 2, and 4. That is, 3.12\% for CFRTP with 8 plies, $1.00 \%$ for CFRTP with 9 plies, and $1.80 \%$ for CFRTP with 10 plies. Nondimensional standard deviations of fiber contents by combustion are 3.94\% for CFRTP with 8 plies, $1.07 \%$ for CFRTP with 9 plies, and $1.19 \%$ for CFRTP with 10 plies. Those of fiber contents by TG are $3.58 \%$ for CFRTP with 8 plies, $1.87 \%$ for CFRTP with 9 plies, and $3.58 \%$ for CFRTP with 10 plies. The deviation by the operators of RRT in this paper should be negligible, since all the operators of RRT are experts as described in Experimental part. The accuracies of fiber contents by both of combustion and TG are reasonable comparing with estimated distribution of fiber contents of samples.

The RRT in this paper is considered as the RRT by experts. On this account and the fact that numbers of measurements in the organizations were not unified, the analysis of RRT is done according to the standards such as ISO 5725 series and ASTM E691.

\section{Conclusions}

A new method for the determination of the carbon fiber content of carbon fiber-reinforced plastics (CFRP) using thermogravimetry (TG) based on the ISO standard for determining carbon black content of rubber products was proposed instead of the combustion method or strong acid method regulated by ISO 14127. The resin of CFRTPs was degraded by TG under nitrogen gas and the carbon fiber was degraded by TG under air. The presence of carbon fibers was observed after degradation under nitrogen gas by microscopy. Round robin tests for carbon content measurement according to both the ISO 14127 method and the method proposed in this paper were performed by several organizations in Japan. The fiber contents in weight of the CFRTP with 8 , 9, or 10 plies were determined to be 55.720 $\pm 1.227 \%$, $61.088 \pm 0.461 \%$, or $65.326 \pm 0.433 \%$, respectively, by 17 research institutes. In the thermogravimetry method, the fiber contents of the CFRTP $(\sim 10 \mathrm{mg})$ were determined by the mass of carbon fiber remaining after heating it to $600^{\circ} \mathrm{C}$ in nitrogen gas using thermogravimetry apparatus (modified ISO 9924-3). The fiber contents of the CFRTP with 8,9 , or 10 plies were determined to be $56.908 \pm 1.598 \%$, $61.579 \pm 0.678 \%$, or $64.819 \pm 0.751 \%$, respectively, by 8 research institutes. The standard deviation among the results obtained by different organizations was almost $2 \%$, which was considered acceptable for reasonable evaluation of the carbon fiber content. This new, safe, and simple method of determining the fiber content of CFRTP samples will be proposed by the author to be included under ISO/TC 61, "Plastics." The title of the new proposal for the ISO will be "Carbon-Fiber-Reinforced Composites-Determination of Fiber Weight Content by Thermogravimetry (TG).”

\section{Appendix}

\section{A. Institutions Participating in Fiber Content Determination by Combustion Method}

(i) Toyama Industrial Technology Center

(ii) Industrial Technology Center of Tochigi Prefecture

(iii) Saitama Industrial Technology Center

(iv) Industrial Research Institute of Shizuoka Prefecture

(v) Hamamatsu Industrial Research Institute of Shizuoka Prefecture

(vi) Industrial Research Center of Shiga Prefecture

(vii) Northeastern Industrial Research Center of Shiga Prefecture

(viii) Kyoto Municipal Institute of Industrial Technology and Culture

(ix) Nara Prefecture Institute of Industrial Development

(x) Osaka Municipal Technical Research Institute

(xi) Osaka Research Institute of Industrial Science and Technology

(xii) Hiroshima Prefectural Technology Research Institute

(xiii) Industrial Technology Center of Okayama Prefecture

(xiv) Yamaguchi Prefectural Industrial Technology Institute

(xv) Kochi Prefectural Industrial Technology Center

(xvi) Fukuoka Industrial Technology Center

(xvii) Oita Industrial Research Institute.

\section{B. Institutions Participating in Fiber Content Determination by Thermogravimetry Method}

(i) Toyama Industrial Technology Center

(ii) Industrial Research Institute of Shizuoka Prefecture

(iii) Industrial Research Center of Shiga Prefecture

(iv) Northeastern Industrial Research Center of Shiga Prefecture 
(v) Nara Prefecture Institute of Industrial Development

(vi) Technology Research Institute of Osaka Prefecture

(vii) Yamaguchi Prefectural Industrial Technology Institute

(viii) National Institute of Advanced Industrial Science and Technology (AIST).

\section{Institution Participating in Fiber Content Determination by Acid Degradation Method}

(i) Industrial Research Institute of Shizuoka Prefecture.

\section{Conflicts of Interest}

The authors declare that they have no conflicts of interest.

\section{Acknowledgments}

RRT in this study was performed as part of a program to support the advancement of technology, run by the Industrial Technology Cooperative Promotion Committee (Japan) with AIST from 2013 to 2016.

\section{References}

[1] J. Pola, "Composite materials in the Airbus A380-From history to future," http://www.iccm-central.org/Proceedings/ ICCM13proceedings/SITE/PAPERS/paper-1695.pdf.

[2] J. Hale, "Boeing 787 from the ground up," Aero, vol. 20, pp. 1723, 2006.

[3] T. Shinoda, H. Odani, E. Wadahara, Y. Komori, and T. Shono, "A-VaRTM technology application for Japan's new regional jet aircraft," http://www.iccm-central.org/Proceedings/ICCM16proceedings/contents/pdf/MonA/MoAM1-04sp_shonot224571p.pdf.

[4] T. Hayashi, "Car production by CFRP," Automotive Technology, vol. 5, pp. 40-55, 2012.

[5] Toray official web site, http://www.toray.com/ir/pdf/lib/lib_al36.pdf.

[6] M. Hamada, "Car production by CFRTP," Automot. Technol, vol. 3, pp. 64-69, 2014.

[7] P. Feraboli, H. Kawakami, B. Wade, F. Gasco, L. DeOto, and A. Masini, "Recyclability and reutilization of carbon fiber fabric/epoxy composites," Journal of Composite Materials, vol. 46, no. 12, pp. 1459-1473, 2012.

[8] Q. Wang, H. Ning, U. Vaidya, S. Pillay, and L.-A. Nolen, "Development of a carbonization-in-nitrogen method for measuring the fiber content of carbon fiber reinforced thermoset composites," Composites Part A: Applied Science and Manufacturing, vol. 73, pp. 80-84, 2015.

[9] G. Wróbel, G. Muzia, and S. Pawlak, "Active IR-thermography as a method of fiber content evaluation in carbon/epoxy composites," Archives of Materials Science and Engineering, vol. 30, no. 2, pp. 101-104, 2008.

[10] G. Wróbel, Z. Rdzawsiki, G. Muzia, and S. Pawlak, "Determination of thermal diffusivity of carbon/epoxy composites with different fiber content using transient thermography," Journal of Achievements in Materials and Manufacturing Engineering, vol. 37, no. 2, pp. 518-525, 2009.
[11] M. Kunioka, K. Taguchi, F. Ninomiya, M. Nakajima, A. Saito, and S. Araki, "Biobased contents of natural rubber model compound and its separated constituents," Polymer, vol. 6, no. 1, pp. 423-442, 2014.

[12] K. Shimizu, Y. Tokuta, A. Oishi, T. Kuriyama, and M. Kunioka, "Weatherability of Polypropylene by Accelerated Weathering Tests and Outdoor Exposure Tests in Japan," Journal of Polymers, vol. 2016, Article ID 6539567, 14 pages, 2016. 

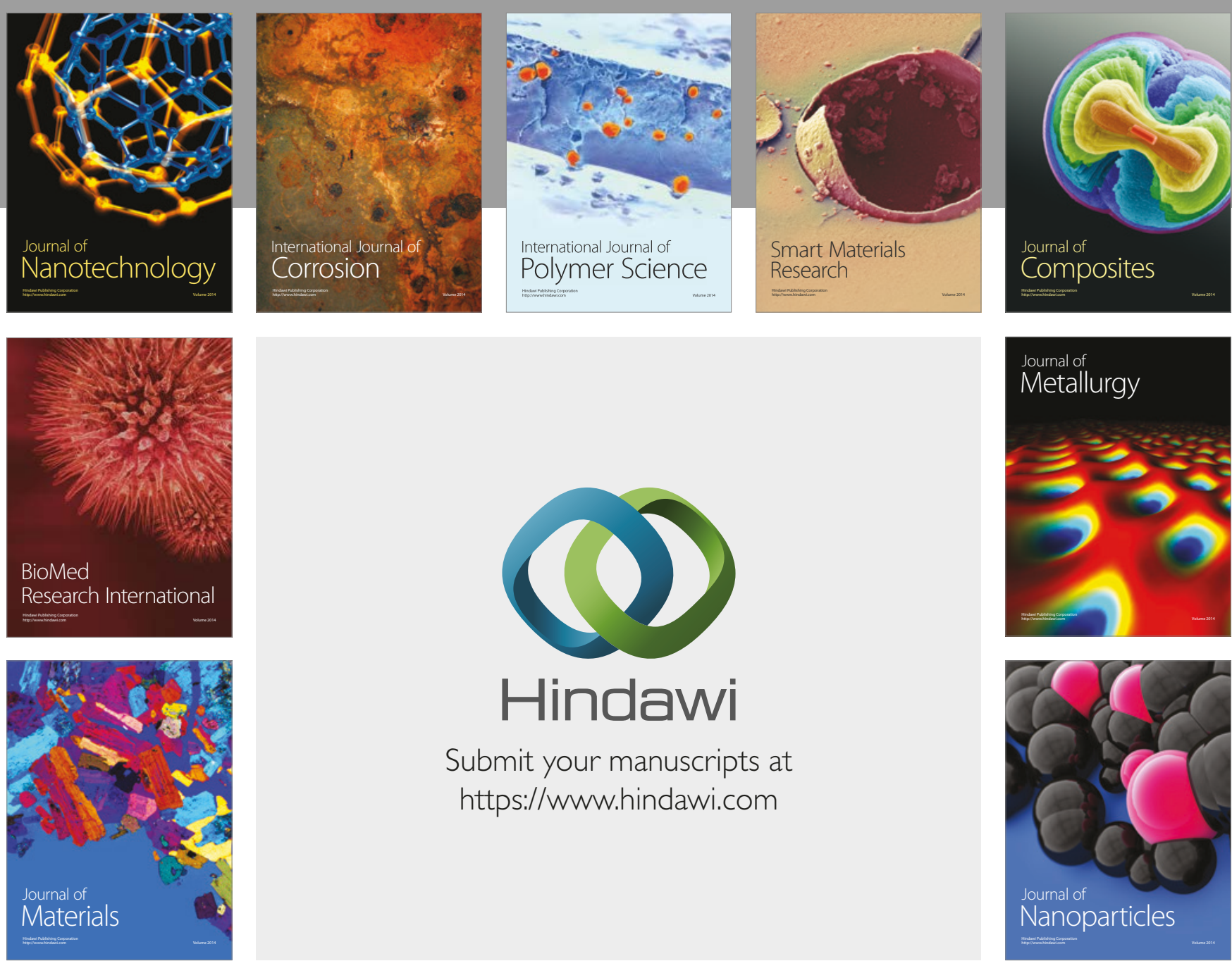

\section{Hindawi}

Submit your manuscripts at

https://www.hindawi.com
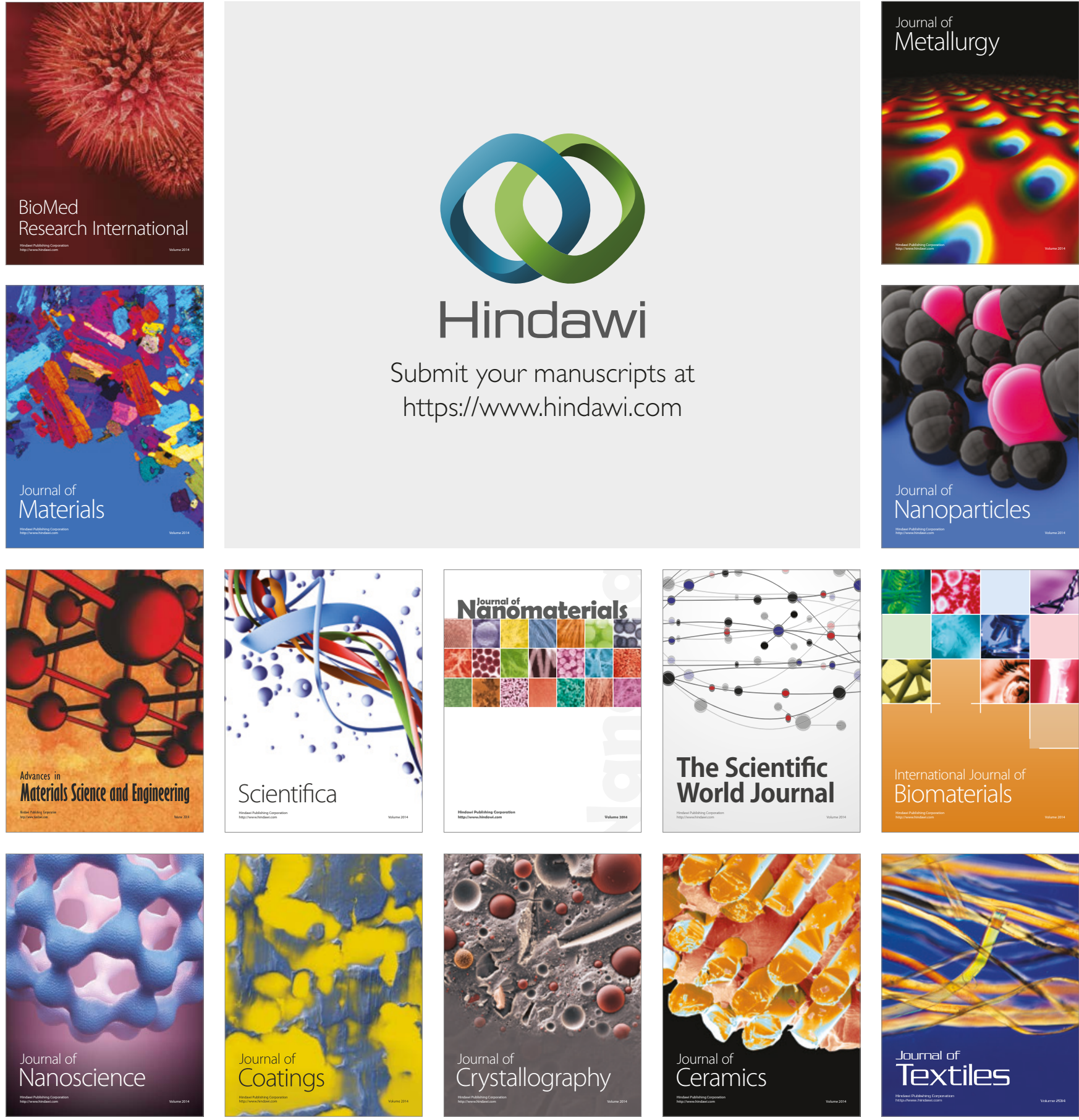

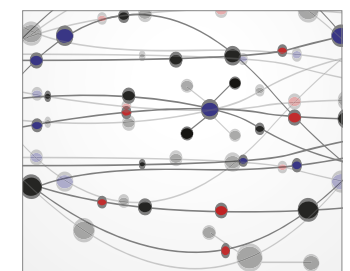

The Scientific World Journal
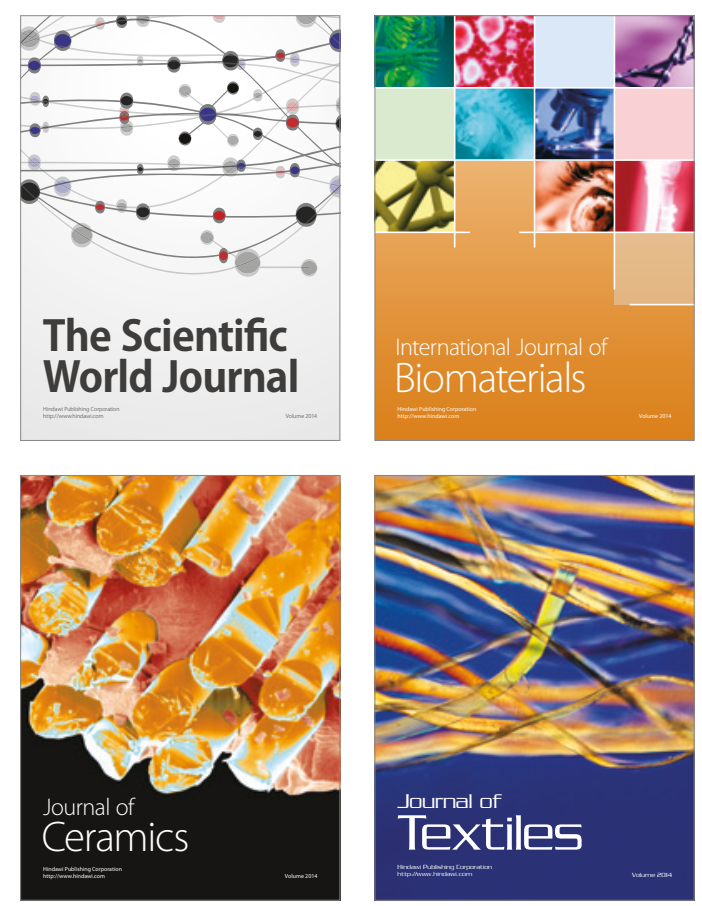